\title{
REGENERATION IN EUDRILUS EUGENIAE KINBERG 1867 (OLIGOCHAETA, ANNELIDA)
}

\author{
${ }^{1}$ Anu Anto*, ${ }^{2}$ Mary Jomon, ${ }^{3}$ Neenu Pavithran, ${ }^{4}$ Sruthy Vasu, ${ }^{5}$ Nimisha Nedumparambil Shaju \\ ${ }^{1}$ Assistant Professor, Department of Zoology, \\ St. Xavier's College for Women, Aluva-683101, Kerala, India \\ ${ }^{2}$ School of Environmental Sciences, Cochin University of Science and Technology, \\ Kochi-682022, Kerala, India, e-mail:maryjomon1@gmail.com \\ ${ }^{3}$ Department of Marine Biology, Microbiology and Biochemistry, \\ Cochin University of Science and Technology, Kochi-682016, Kerala, India. \\ e-mail: neenupavithran9@gmailcom \\ ${ }^{4}$ Department of Marine Biology, Microbiology and Biochemistry, \\ Cochin University of Science and Technology, Kochi-682016, Kerala, India. \\ e-mail:sruthyvasutc@gmail.com \\ ${ }^{5}$ Department of Zoology, St.Albert's College, Ernakulam-682018, Kerala, India \\ e-mail:nimishashaju29@gmail.com \\ *Corresponding author email id: anuanto@stxaviersaluva.ac.in
}

\begin{abstract}
Earthworm EudriluseugeniaeKinberg 1867, commonly known as African night crawler is an efficient organic waste decomposer. As the dedifferentiation patterns of these invertebrates are like vertebrates, they are excellent candidates for regeneration studies. We made 12 amputations along the earthworm to demarcate anterior and posterior sections for regeneration studies. Regeneration events included wound healing, blastema formation, segmentation, pigmentation and functional clitellum formation. Clitellum formation was noted in the posterior segments after 28-30 days of amputation, whereas anterior segments without clitellum did not survive after 30 days. In both anterior and posterior segments, number of segments remaining after amputation proved to be a significant factor in determining the survival rate. Earthworms with less than one fourth of the body length showed very low survival rates.But no significant correlation existed between the lengths of regenerating fragment and number of remaining segments in the amputated worms. Analysis of variance showed no significant difference between regeneration rates of different segments in anterior segments whereas the posterior segments showed significant difference in the regeneration rates.
\end{abstract}

KEYWORDS: African night crawler, earthworm, blastema, clitellum, regeneration

\section{INTRODUCTION}

Regeneration has been studied in a wide variety of invertebrates such as planarians $^{1}$, hydras ${ }^{2,3}$ and earthworms ${ }^{4,5}$. The process behind regeneration from planaria to amphibian limb is similar with the formation of blastema, a proliferative mass of undifferentiated progenitor cells from which new differentiated cells arise ${ }^{6,7}$. Earthworms are used for regeneration studies, due to its rapid regenerative power, easy availability and easy maintenance in laboratory conditions ${ }^{8}$. Studies on different aspects of regeneration of earthworms were carried out in Perionyx excavates ${ }^{\mathbf{1 0}}$, Eisenia fetida $^{11}$ and Eudriluseugeniae ${ }^{4,5,12}$. More extensive studies based on the position of amputation on survival and regeneration in $E$. eugeniae are lacking.

Is the regeneration capacity of the earthworm E.eugeniae influenced by the position of the amputation. Studies 
conducted by Xiao et. $a l^{4}$ and Gates ${ }^{13}$ in E.fetida pointed out that regeneration capacity and survival rate decreased as more segments were amputated.

This paper aims to study whether regeneration and survival rate in E.eugeniae also conforms to the same pattern or does it differ? Also, this study investigates the various events taking place in regeneration of segments of E. eugeniae such as formation of clitellum, cocoon etc. in clitellum amputated ones.

\section{MATERIALS AND METHODS}

E.eugeniae (African night crawler) is 90-185 mm length, 5-8 mm diameter andhas 145-196 segments; mature worms have typically 162 segments. Body is subdivided into three regions viz., preclitellar (1-12 segments), clitellar (13-18 segments) and postclitellar (from the $19^{\text {th }}$ to the end of the body). For the experiment adult E.eugeniaewith 14-18 preclitellar and 144 post clitellar segments were selected. In the lab worms were kept in cow manure at 26 $\pm 2^{\circ} \mathrm{C}$ and 75 to $85 \%$ humidity.

Two types of amputation treatments were used (i) anterior parts of earthworms whose posterior segments were removed (A) and (ii) posterior parts of earthworms whose anterior segments were removed $(\mathrm{P})$. Amputation (A) generated six types of anterior segments viz., A3, A14, A18, A41, A81 and A121 and amputation (B) also generated six types of posterior segments, P4, P15, P19, P42, P82 and P122 (Fig. 1).

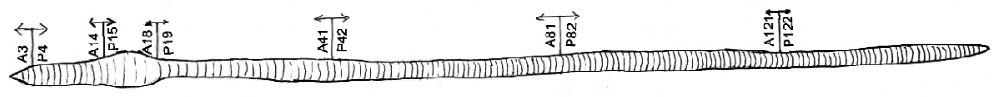

Figure 1. Amputations done in anterior (A) and posterior (P) regions of Earthworm Eudrilus eugeniae.

A total of 12 different sections of body segments were amputated for survival experiments and nine sections were used for regeneration experiments. (Table 1). Clitellum was lacking in segments A3, A14, P19, P42, P82 and P122. Segments A41 and P122 represented (1/4) of body length; A81 and P82 (1/2); A121 and P42 represented $(3 / 4)$ of the total body length (Table 1 ). Controls were earthworms with no amputations. All twelve amputation treatments were replicated two times with 15 earthworms per treatment.

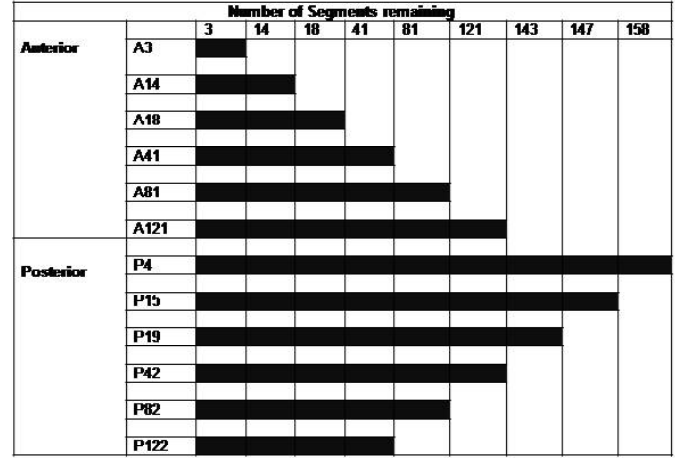

Table 1. Positions of Eudrilus eugeniae amputations with remaining segments 
Earthworms were placed over ice to slow down its activity ${ }^{14}$ and amputated by placing them under a stereozoom microscope. Earthworms were then kept in $150 \mathrm{ml}$ earthern pot with cow manure under controlled lab conditions. The survival and regeneration rates of amputated earthworms were checked every 5 days for 110 days. Medium was also searched for earthworms with newly developed clitellum and cocoons in clitellum amputated ones.

The data were analyzed using XLSTAT365 program. Pearson Correlation was used to analyze correlation coefficients between the survival rates and lengths of remaining segments. Analysis of Variance (ANOVA) was used to check whether the regeneration rates differ among various anterior and posterior segments. The probability level used for the statistical significance was $\mathrm{P}<0.05$.

\section{RESULTS AND DISCUSSION}

Events happening during regeneration of Eudrilus eugeniae

After amputation in earthworm E.eugeniae the complex process of regeneration started with the wound healing process. Initially, coagulation was noticed within few minutes at the wounded sites of all amputated earthworms ${ }^{15}$. This was in accordance with the findings by Subramanian et. $a l^{\mathbf{1 6}}$ in E. eugeniae. In earthworm E.fetida, after 4 hours of amputation wound closure becomes apparent ${ }^{4}$, wound healing seems to be a species-specific process and variation could be observed based on physico chemical factors too. Finally, the wound closures of every anterior and posterior amputated earthworms were observed on the second day of post amputation. Next step in regeneration process is blastema formation. On the $3^{\text {rd }}$ day of post amputation under stereozoommicrosope it was found that blastema appeared as a colourless mass of freshly formed tissue.This too agreed with findings reported by Subramanian et $\mathrm{al}^{16}$ in E. eugeniae. Segmentation started in the newly formed blastema on $12 \pm 2$ days. In E. fetida segmentation was noted 7-11 days after amputation ${ }^{4}$. On the $17 \pm 1$ day, pigmentation of regenerated cells was initiated and was completed on $44 \pm 2$ days, making it difficult to differentiate between regenerated and non-regenerated ones. Organogenesis studies conducted on $E$. eugeniae showed that, on day six, an abundance of differentiated cells was present in the regenerating anterior and posterior regions ${ }^{16}$. Clitellum formation was noted between 28-30 days and formation of cocoons was noted on $32^{\text {nd }}$ day in clitellum amputated posterior segments (P19, P42, $\mathrm{P} 82$ and P122). Similar findings were made by Coulibaly and Zoro Biand Byambas et al ${ }^{18}$ with fresh non-amputated E. eugeniae. They noticed that the production of cocoons started five weeks after the beginning of the breeding. Reineck et $\mathrm{al}^{\mathbf{1 9}}$ and Dominguez et $\mathrm{al}^{\mathbf{2 0}}$ reported that the time from hatching to production of cocoons in E.eugeniae as $47 \pm 3$ days. The relatively fast multiplication of earthworms would be also result from 
the temperature of the breeding environment of E. eugeniae en,21 $^{2}$ No cocoon formation was observed in anterior segments without clitellum as they did not survive after 30 days (Table 2).

Table 2. Events happening during regeneration of Eudrilus eugeniae

\begin{tabular}{|l|l|}
\hline $\begin{array}{l}\text { Events happening during } \\
\text { regeneration }\end{array}$ & Duration \\
\hline Coagulation of Wound & Few minutes \\
\hline Wound Closure & Two days \\
\hline Blastema Formation & Three days \\
\hline Segmentation & $12 \pm 2$ days \\
\hline Initiation of pigmentation & $17 \pm 1$ day \\
\hline Formation of Clitellum & $28-30$ days \\
\hline Cocoon formation & $32^{\text {nd }}$ day \\
\hline Pigmentation completed & $44 \pm 2$ days \\
\hline Compost formation & 49 days \\
\hline
\end{tabular}

Survival rates of earthworms amputated at different segments

The survival rates of the anterior segments of mature earthworms after removal of different lengths of posterior segments are summarized in Figure 2A. After 110 days, amputation treatments A42, A 82 and A121 had a high survival rate with $100 \%, 90 \%$ and $100 \%$ respectively. The segments A3 and A14, ones without clitellum had the lowest survival rates of $0 \%$. All the A3 earthworms died within 15 minutes after cutting it. In the earthworms with anterior segments amputated, positive correlation existed between survival rates (Y) and the numbers of remaining segments
(X) $(\mathrm{R}=0.82, \mathrm{~F}=20.71, \mathrm{P}<0.05) . \quad$ As $E$. eugeniae is a tropical eudrilid earthworm from Africa, its fecundity, growth, maturation and biomass production were all greatest at $25^{\circ} \mathrm{C}$ and we could maintain our culture at an average temperature of $25-27 \mathrm{p}$ $\mathrm{C}$, ambient for growth and reproduction of these worms., which is higher than the optimal temperatures quoted for other species that inhabit temperate habitats ${ }^{9}$.

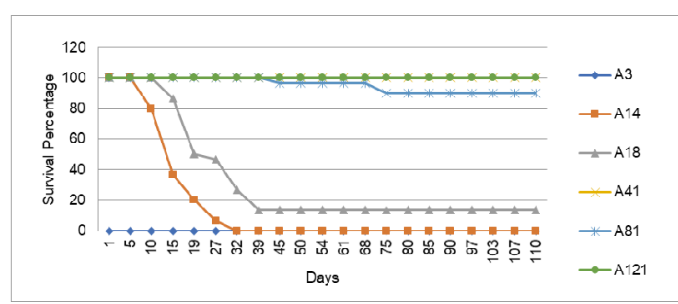

Figure 2A. Survival rate of clitellate adult earthworm after posterior region amputations.

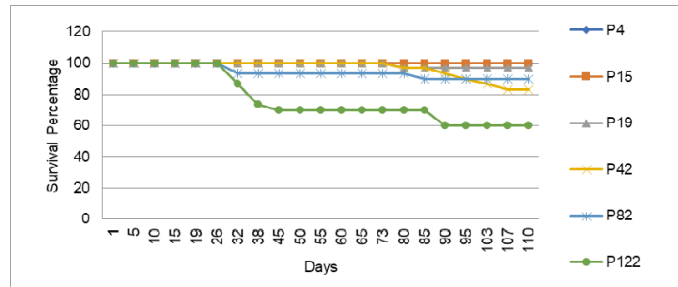

Figure 2B. Survival rate of clitellate adult earthworm after anterior region amputations.

Rate-time curves for survival of the posterior segments of mature earthworms after anterior parts were amputated are shown in (Figure3B). 100\% of earthworms at $\mathrm{P} 4$ and $\mathrm{P} 15$ treatment survived 110 days. The survival rate of earthworms in the P19, P42 and P82 amputation treatments was above $80 \%$. All the earthworms with the P121 amputation treatment have the least survival rate of $60 \%$. Earthworms with 
posterior segments amputated showed positive correlation between survival rates (Y) and the numbers of remaining segments (X) $(\mathrm{R}=0.799, \mathrm{~F}=17.77, \mathrm{P}<0.05)$.Earlier authors have reported correlation of the survival rate and regeneration capacity of mature E. fetida indicating that higher the number of segments remaining in the amputated earthworm, the greater was the chances of survival and regeneration ${ }^{4}$. Saha et $a .^{22}$, confirmed that absence of vital organs in the amputated segments did not support survival and regeneration of the amputee E. fetida worms.

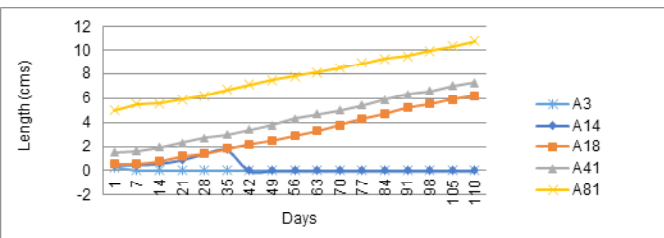

Figure 3A. Regeneration of segments in earthworm after posterior segment amputations.

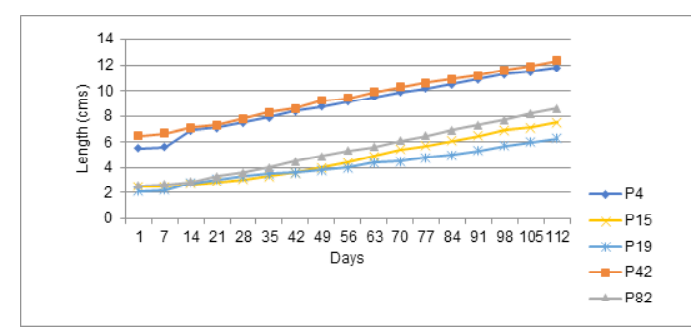

Figure 3B. Regeneration of segments in earthworm after anterior segment amputations.

\section{Regeneration rates of earthworm amputated at different segments}

In both posterior and anterior segments no significant correlation existed between the lengths of regeneration and number of segments remaining $(\mathrm{R}=0.508, \mathrm{P}>0.05)$ (Figure 3A,B). Amputation treatments A41 and A81 exhibited high levels of regeneration and survival during the period of experiment (110 days). Though initially a peak in regeneration rate was observed in A81, later the rates of all segments showed no difference. Analysis of Variance (ANOVA) showed no significant difference between regeneration rates of different segments $(\mathrm{F}=2.112, \mathrm{df}=3, \mathrm{P}>0.05)$ (Figure $4 \mathrm{~A})$. In the posterior segments, $\mathrm{P} 4$ segment showed high rates of regeneration and survival. Analysis of Variance (ANOVA) showed significant difference in the regeneration rates of different segments in the posterior region $(\mathrm{F}=16.65, \mathrm{df}=4, \mathrm{P}<0.05)$ (Figure 4B). Our results support the findings reported in E. fetida by Xiao et al. ${ }^{4}$, that the length of regeneration did not depend upon

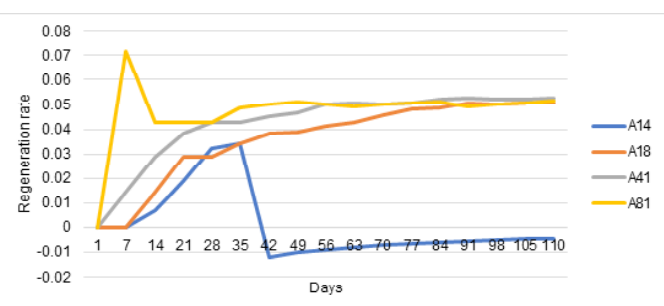

Figure 4A. Regeneration rate of anterior segments of mature earthworms after posterior segments were amputated.

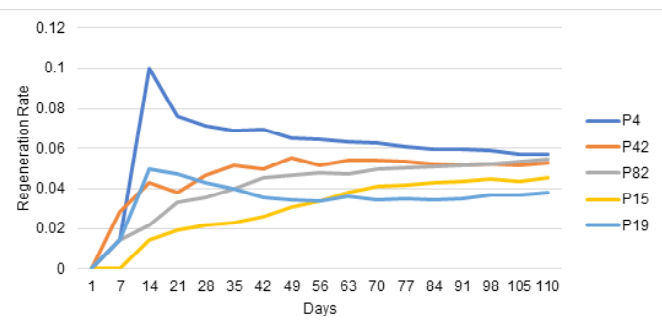

Figure 4B. Regeneration rate of posterior segments of mature earthworms after anterior segments were amputated. 
the no. of segments remaining or upon the position of amputation of posterior segments but did depend significantly on the amputation of anterior segments. These results do not hold Morgan's law, which accounts only for posterior regeneration, indicating noticeably that the posterior segments had a greater regeneration capacity than the anterior segments. The present study has summarized the morphological events observed during anterior and posterior regeneration in E. eugeniae, the African crawler worm, more intricate cellular mechanisms could be revealed on future investigations on these model organisms.

\section{REFERENCES}

1. Gurley, K.A., J.C. Rink and A.S. Alvarado, 2008. â-Catenin defines head versus tail identity during planarian regeneration and homeostasis. Science, 319: 323-327.

2. Broun, M., L. Gee, B. Reinhardt and H.R. Bode, 2005. Formation of the head organizer in hydra involves the canonical WNT pathway. Development., 132: 2907-2916.

3. Hobmayer, B., F. Rentzsch, K. Kuhn, C.M. Happel, C.C. von Laue, P. Snyder, U. Rothbächer and T.W. Holstein, 2000. WNT signalling molecules act in axis formation in the diploblastic metazoan Hydra. Nature, 407: 186-189.

4. Xiao, N., F.G. Clive and A. Edwards, 2011. The regeneration capacity of an earthworm, Eisenia fetida, in relation to the site of amputation along the body. Acta Ecologica Sinica., 31:197-204.

5. Samuel S. C. J. R., S.E. Raja, Y.B. Vedha, A.E.A. Jane, K. Amutha, S.M. Dinesh, S.C.J. Durairaj, R.M. Kalidas, V. Tharmaraj, K. Pitchumani and S. Sudhakar, 2011. Autofluorescence in BrdU-positive cells and augmentation of regeneration kinetics by riboflavin. Stem cells Dev., 21: 2071-2083.

6. Brockes, J.P. and A. Kumar, 2005. Appendage regeneration in adult vertebrates and implications for regenerative medicine. Science., 310: 1919-1923.

7. Reddien, P.W. and S.A. Alvardo, 2004. Fundamentals of planarian regeneration. Annu. Rev. Cell Dev. Biol., 20:725-757.

8. Edwards, C.A. and P.J. Bohlen, 1996. Biology and Ecology of Earthworms. $3^{\text {rd }}$ ed. London, UK: Chapman and Hall Ltd. pp. 426.

9. Edwards, C.A., J. Dominguez and E.F. Neuhauser, 1998. Growth and reproduction of Perionyx excavatus (Perr.) (Megascolecidae) as factors in organic waste management. Biol. Fertil. Soils., 27: 155161.

10. Perrier, E., 1872. Recherches pour servir a l'histoire des Lombriciens terrestres. Nouvelles annals du Museum d'historie naturelle, 8: 5-198.

11. Savigny, J.C., 1826. Analyses des travaux de l'Academie Royale des Sciences pendant l'annee 1821, partie physique. Mémoires de l'Académie des sciences de l'Institut de France., 5: 176-184.

12. Kinberg, J.G.H., 1867. Annulata nova. Öfersigt af Kungliga Svenska Vetenskaps-Akademiens Förhandlingar, Stockholm. 23 (4): 97-103.

13. Gates, G. E, 1949. Regeneration in an earthworm, Eisenia foetida (Savigny) 1826. I. Anterior regeneration. Biol. Bull., 96:129-139.

14. Qi, I.P., F. Ge \& D. Zhou, 2002. On the regenerative capacity of the earthworm, Eisenia fetida.Ying Yong Yu Huan Jing Sheng Wu Xue Bao., 5: 276-279.

15. Gurtner, G.C., S. Werner, Y. Barrandon and M.T. Longaker, 2008. Wound repair and regeneration. Nature, 453: 314-321.

16. Subramanian, E. R., D.K. Sudalaimani, S.C.J.R. Samuel, K. Ramamoorthy, N.G. Daisy, J. D.S. Christyraj, K. Renganathan, S. Krishnan and S. Sivasubramaniam, 2016. Studies on organogenesis during regeneration in the earthworm, Eudrilus eugeniae, in support of 
symbiotic association with Bacillus endophyticus. Turk. J. Biol., 41:113-126.

17. Coulibaly, S.S. \& I.A. Ziro Bi, 2010. Influence of animal wastes on growth and reproduction of the African earthworm species Eudrilus eugeniae (Oligochaeta). Eur. J. Soil Biol., 46: 225-229.

18. Byambas, P., A. Lemtiri., F. Francis, T.B. Ndong., and J.L. Hornick, 2017. Effect of cow dung and manure of laying hens on growth and reproduction of Eudrilus eugeniae in Gabon. Int. J. Agric. Biol., 19: 921-927.

19. Reinecke, A.J., S.A. Viljoen and R.J. Saayman, 1992. The suitability of Eudrilus eugeniae, Perionyx excavatus and Eisenia fetida (Oligochaeta) for vermicomposting in southern Africa in terms of their temperature requirements. Soil Biol.Biochem., 24: 12951307.

20. Dominguez, J., C.A. Edwards and J. Ashby, 2001. The biology and ecology of Eudrilus eugeniae (Kinberg) (Oligochaeta) bred in cattle wastes. Pedobiologia., 45: 341-353.

21. Francis, F., E. Haubruge, P.T. Thang, L.V. Kinh, P. Lebailly and C. Gaspar, 2003. Technique de Lombriculture au sud Vietnam. Biotechnol. Agron. Soc. Environ., 7:171-175.

22. Saha, T., A.K. Chakravarty and R. Chakraborty, 2016. Dynamics of Regeneration process in Eisenia fetida.North Beng. Univ. J. Anim. Sci., 10: 79-88. 